\title{
Effects of Topography on Tree Community Structure in a Deciduous Broad-Leaved Forest in North-Central China
}

\author{
Hang Shi ${ }^{1,2}$, Fenglin Xie ${ }^{1,3,4}$, Quan Zhou ${ }^{1,2}$, Xiao Shu ${ }^{1}$, Kerong Zhang ${ }^{1}$, Chaoqi Dang ${ }^{5}$, \\ Shuiyuan Feng ${ }^{6}$, Quanfa Zhang ${ }^{1}$ and Haishan Dang ${ }^{1, *}$ (i) \\ 1 Key Laboratory of Aquatic Botany and Watershed Ecology, Wuhan Botanical Garden of the Chinese \\ Academy of Sciences, Wuhan 430074, China; hangge1993@outlook.com (H.S.); fenglinx94@126.com (F.X.); \\ 18689881823@163.com (Q.Z.); shuxiao198259420@sina.com (X.S.); kerongzhang@wbgcas.cn (K.Z.); \\ qzhang@wbgcas.cn (Q.Z.) \\ 2 The University of Chinese Academy of Sciences, Beijing 100049, China \\ 3 Research Center for Ecology and Environment of Qinghai-Tibetan Plateau, Tibet University, Lhasa 850000, \\ China \\ 4 College of Science, Tibet University, Lhasa 850000, China \\ 5 Shaanxi Meteorological Service Center, Xi'an 710014, China; maoniao30@sina.com \\ 6 Foping National Nature Reserve, Foping 723400, China; fengshuiy123456@163.com \\ * Correspondence: dangkey@wbgcas.cn; Tel.: +86-27-8770-0867; Fax: +86-27-875-1025
}

Received: 30 November 2018; Accepted: 8 January 2019; Published: 11 January 2019

\begin{abstract}
Topography strongly influences the compositional structure of tree communities and plays a fundamental role in classifying habitats. Here, data of topography and 16 dominant tree species abundance were collected in a fully mapped 25-ha forest plot in the Qinling Mountains of north-central China. Multivariate regression trees (MRT) were used to categorize the habitats, and habitat associations were examined using the torus-translation test. The relative contributions of topographic and spatial variables to the total community structure were also examined by variation partitioning. The results showed the inconsistency in association of species with habitats across life stages with a few exceptions. Topographic variables $[a+b]$ explained $11 \%$ and $19 \%$ of total variance at adult and juvenile stage, respectively. In contrast, spatial factors alone [c] explained more variation than topographic factors, revealing strong seed dispersal limitation in species composition in the 25-ha forest plot. Thus, the inconsistent associations of species and habitats coupled with high portion of variation of species composition explained by topographic and spatial factors might suggest that niche process and dispersal limitation had potential influences on species assemblage in the deciduous broad-leaved forest in north-central China.
\end{abstract}

Keywords: the Qinling Mountains; variation partitioning; torus-translation test; niche theory; dispersal limitation

\section{Introduction}

One of the worldwide hotspots in ecological research is to understand the mechanisms that influence the spatial structure in community assembly. The niche differentiation is an important theory for the maintenance of species diversity in complex forest communities [1,2]. For niche differentiation, biotic process stated that multi-species remained in coexistence through interspecies competition for acquiring similar resource, while abiotic rule considered that habitat filtering [3] was a critical process in shaping ecological communities. However, neutral process related to dispersal limitation and 
ecological drift might also play an important role in shaping distribution structure of tree communities and lead to aggregated seedling and adult populations [4].

The relationships between tree species and habitats in forests are essential for understanding the process of species distribution [5]. Simultaneously, for some spatially structured habitat components, such as topographic or edaphic variables, they could be reflected in species distribution by habitat associations [5]. Due to its influences on water availability and soil property, topography always acts as a useful proxy for habitat heterogeneity [5-7]. In addition, topography usually serves as a basis for defining habitats. In order to define the notably different habitat features with similar species composition, De'Ath [8] proposed the multivariate regression trees (MRT) to categorize the area into different habitats.

Given the associations of species distribution and habitats, many recent studies have illustrated theoretical explanation with respect to the contradiction of niche differentiation and limited dispersal [4,9-11]. Specifically, due to the mechanisms of niche differentiation and dispersal limitation, on species level, habitat preferences are always consistent or not across life stages in tropical, subtropical and temperate forests. Considering habitat partitioning at early life stage in a more heterogeneous environment, it may partially be a compensation of niche separation at adult stage [12]. If habitat filtering governs community assembly, stronger habitat associations can be expected at juvenile stage [11]. Otherwise, there may be weaker habitat associations at later stage, in which case competition controls species distribution $[13,14]$. If limited dispersal dominants in shaping community assembly, it will drive consistent habitat preferences across all life stages $[13,15]$.

In general, species assemblage at community scale is controlled mainly by habitat filtering and relatively large competition is found among similar species [16], while the influence of dispersal limitation should display to be more significant at local scale (less than $1 \mathrm{Km}^{2}$ ) [13]. Substantial studies emphasized the contributions of topographic factors and spatial components to shaping community structures. Gilbert and Lechowicz [17] firstly assessed the relative importance of environment control and spatial structure in comparison of limited dispersal and niche partitioning. Recently, Baldeck, et al. [13] compared the influence of habitat filtering and dispersal limitation on compositional structure of tropical forest based on soil, topography and spatial variables, and Lan, et al. [18] demonstrated the relative importance of topographic and spatial variables on species distribution.

The Qinling Mountains are located in the transitional zone from temperate region in the northern slope to the subtropics in southern slope in terms of climate in north-central china. The vegetation is diverse due to the coexistence of both the northern and southern Chinese taxa. However, it remains unclear how topography impacts tree community structure in the Qinling Mountains. In this study, we identified the habitat associations and determined the influences of topography and space on species distribution in a deciduous broad-leaved forest in the Qinling Mountains. The objectives of this study were: (1) identify to what extent the forest showed pronounced habitat associations and whether it was consistent across life stages; (2) examine how much variation of species composition could be explained by topographic and spatial variables; and (3) determine the function and importance of niche differentiation and dispersal limitation on species assemblage.

\section{Methods}

\subsection{Study Site}

This study was conducted in the Foping National Nature Reserve $\left(33^{\circ} 33^{\prime}-33^{\circ} 46^{\prime} \mathrm{N}\right.$, $107^{\circ} 40^{\prime}-107^{\circ} 55^{\prime}$ E) on the south-facing slope of the Qinling Mountains, north-central China. Owing to the east to west arrangement, the Qinling Mountains act as an important geographic demarcation line and the most critical boundary for climate and vegetation distribution in central mainland of China [19]. The Qinling Mountains separate semi-arid area and humid regions and the climate conditions are quite different between the north- and south-facing slope. The north-facing slope belongs to warm-temperature zone with relatively dry summer and cold winter, while the south-facing 
slope is in subtropical zone with relatively wet summer and warm winter [20]. In the study area, the annual precipitation ranges from $950 \sim 1200 \mathrm{~mm}$, most of which occurs between July and September. The average annual temperature is $13^{\circ} \mathrm{C}$. The hottest month is July with an average daily temperature of $27^{\circ} \mathrm{C}$, and the coldest month is January with an average daily temperature of $-2{ }^{\circ} \mathrm{C}$ [21]. The soil is slight acid yellow brown soil [22]. With the elevation ranging from 980 to $2900 \mathrm{~m}$, the vegetation has a completely vertical distribution under the sub-tropical monsoon climate. The regional vegetation mainly consists of deciduous broad-leaved forest (980-2300 m), mixed deciduous broad-leaved and coniferous forest (2300-2500 m), and coniferous forest (2500-2900 m) [23].

\subsection{Data Collection}

A permanent forest dynamics plot with an area of 25 ha $(500 \mathrm{~m} \times 500 \mathrm{~m})$ was established in the deciduous broad-leaved forest in the Foping National Nature Reserve in 2014. The elevation in the plot ranges from 1715.0 to $1836.2 \mathrm{~m}$ a.s.l. This plot contains an amount of complex geographical structure with deep valleys and steep slopes (Figure 1). The 25-ha plot was divided into 625 sub-plots of $20 \mathrm{~m} \times 20 \mathrm{~m}$, and each sub-plot was then subdivided into 16 quadrats of $5 \mathrm{~m} \times 5 \mathrm{~m}$. Within each quadrat, all trees with diameter at breast height $(\mathrm{DBH}) \geq 1 \mathrm{~cm}$ were mapped, identified, measured and tagged. The total number of living individuals in the first census of 2014 was 73,932, consisting of 119 species, 66 genera and 35 families. There were 11 species with more than 1000 individuals, accounting for $39 \%$ of the total individuals in the plot. Mean stand density was 2957 trees/ha. Mean basal area was $0.20 \mathrm{~m}^{2} /$ ha. The 16 dominant tree species with importance value $\geq 1.0$ were selected in this study (Table 1). Importance values were defined as (relative abundance + relative basal area + relative frequency) $/ 3$.

Table 1. The characteristics of the 16 dominant tree species in the 25-ha permanent forest dynamics plot in the Qinling Mountains, north-central China.

\begin{tabular}{|c|c|c|c|c|c|c|c|c|}
\hline Species & $\begin{array}{l}\text { Species } \\
\text { Code }\end{array}$ & Family & $\begin{array}{c}\text { No of } \\
\text { Juveniles }\end{array}$ & $\begin{array}{l}\text { No of } \\
\text { Adult }\end{array}$ & $\begin{array}{l}\text { Branch } \\
\text { Number }\end{array}$ & $\begin{array}{c}\text { Basal Area } \\
\left(\mathrm{m}^{2} / \mathrm{ha}\right)\end{array}$ & $\begin{array}{l}\text { Importance } \\
\text { Value }\end{array}$ & Trees/ha \\
\hline Quercus aliena & Querc & Fagaceae & 569 & 2625 & 515 & 0.923 & 14.3 & 153 \\
\hline Sorbus alnifolia & Sorbu & Rosaceae & 1445 & 485 & 420 & 0.537 & 8.8 & 88 \\
\hline Quercus spinosa & Quercu & Fagaceae & 569 & 968 & 1141 & 0.15 & 8.2 & 106 \\
\hline Pterocarya insignis & Ptero & Juglandaceae & 370 & 115 & 201 & 0.135 & 6.5 & 21 \\
\hline Populus purdomii & Popul & Salidaceae & 6 & 201 & 48 & 0.267 & 4.8 & 9 \\
\hline Prunus conadenia & Prunu & Rosaceae & 141 & 1135 & 480 & 0.141 & 4.5 & 68 \\
\hline Carpinus cordata & Carpi & Betulaceae & 953 & 358 & 489 & 0.195 & 3.8 & 60 \\
\hline Pinus armandii & Pinus & Pinaceae & 236 & 676 & 28 & 0.132 & 3.5 & 47 \\
\hline Bothrocaryum controversum & Bothr & Cornaceae & 66 & 727 & 112 & 0.0933 & 3.1 & 37 \\
\hline Dendrobenthamia japonica & Dendr & Cornaceae & 2466 & 1013 & 1256 & 0.0735 & 2.7 & 173 \\
\hline Euptelea pleiospermum & Eupte & Eupteleaceae & 231 & 385 & 550 & 0.0378 & 1.5 & 35 \\
\hline Acer oliverianum & Acer & Aceraceae & 351 & 128 & 36 & 0.0011 & 1.2 & 22 \\
\hline Lindera obtusiloba & Linde & Lauraceae & 147 & 470 & 211 & 0.0412 & 1.2 & 31 \\
\hline Meliosma cuneifolia & Melio & Sabiaceae & 2075 & 650 & 3468 & 0.0241 & 1.1 & 131 \\
\hline Symplocos paniculata & Sympl & Symplocaceae & 2984 & 743 & 992 & 0.0167 & 1 & 184 \\
\hline Cotoneaster acutifolius & Cotone & Rosaceae & 1929 & 92 & 499 & 0.0028 & 1 & 89 \\
\hline Total & & & 14,538 & 10,771 & 10,446 & 2.7705 & 67.2 & 1254 \\
\hline
\end{tabular}




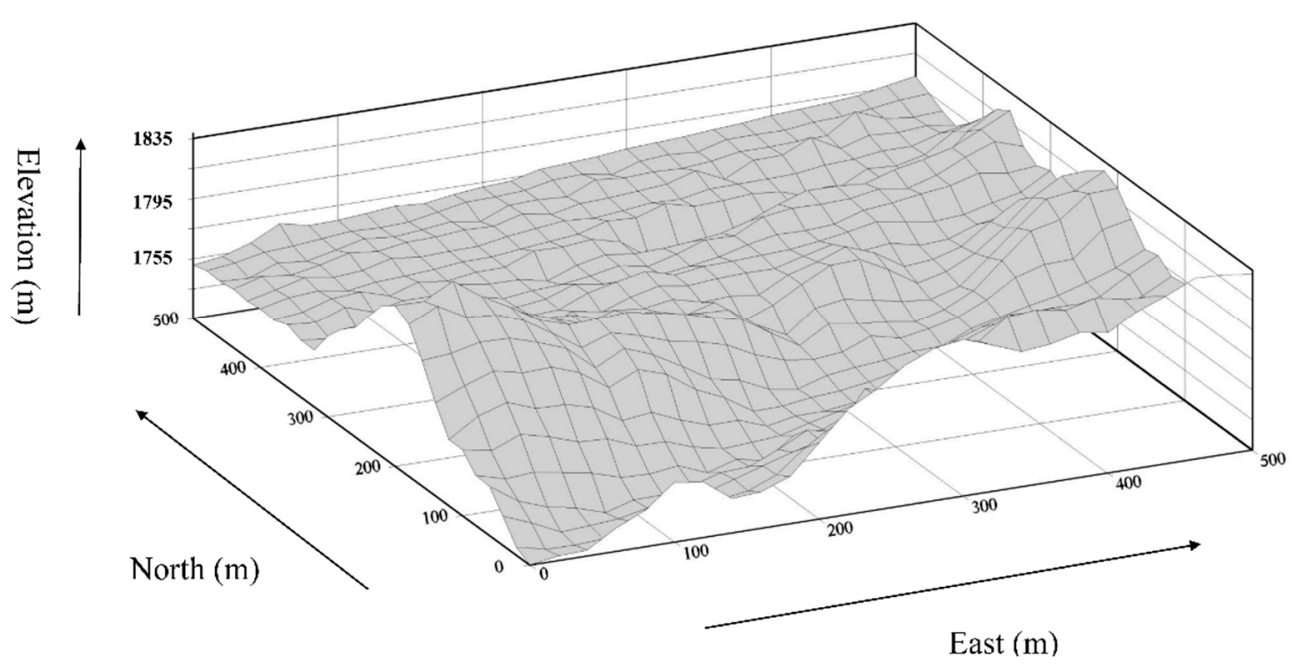

Figure 1. Topographic map of the 25-ha forest plot in the Qinling Mountains of north-central China.

Within each species, trees were ranked by DBH and the 99th percentile (DBH99) determined. All trees were classified into two life stages: Juveniles with $\mathrm{DBH}<\mathrm{DBH} 99^{1 / 2}$, and adults with $\mathrm{DBH}>$ DBH99 ${ }^{2 / 3}$ [24]. In order to strengthen the discrepancy between different DBH classes, the individuals with $\mathrm{DBH}>\mathrm{DBH} 99^{1 / 2}$ and $<\mathrm{DBH} 99^{2 / 3}$ were excluded [24,25].

\subsection{Topographic Variables}

For each of the 625 sub-plots $(20 \mathrm{~m} \times 20 \mathrm{~m}$ ), four topographic variables (elevation, convexity, slope, aspect) were recorded. Elevation was the mean of four corners of the sub-plot [10]. Convexity was defined as the elevation of a focal quadrat minus the mean elevation of eight surrounding quadrats [26]. In particular, convexity of edge quadrats was the difference between the elevation in center point and the mean elevation of four corners. Slope was taken as the average angle of the four planes deviating from the horizontal plane. Aspect referred to the direction of a slope faces [4]. Spatial pattern of four topographic attributes was displayed by showing the elevation (ranging from 1717.15 to $1824.04 \mathrm{~m}$ a.s.1), aspect (ranging from 0.07 to 359.87), slope (ranging from $0.83^{\circ}$ to $75.99^{\circ}$ ) and convexity (ranging from $-9.32 \mathrm{~m}$ to $12.66 \mathrm{~m}$ ) in each cell (Figure 2). 

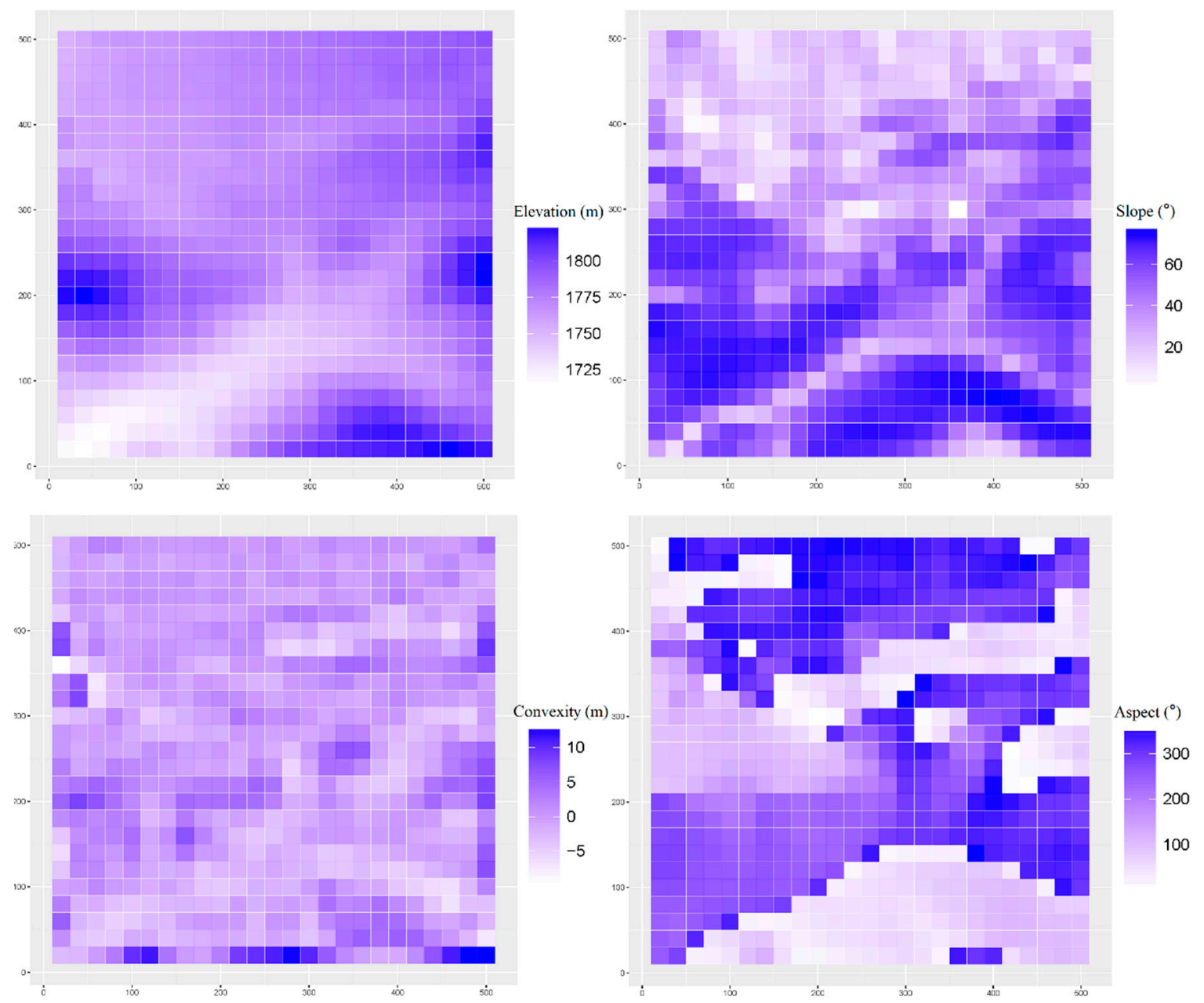

Figure 2. Maps describing the four topographic variables at the scale of $20 \mathrm{~m} \times 20 \mathrm{~m}$ in the 25-ha permanent forest dynamics plot in the Qinling Mountains of north-central China.

\section{Data Analyses}

\subsection{Habitat Definition}

The 625 sub-plots were classified into five habitats: low-slope, high-slope, ridge, low-valley and upper-valley by using the multivariate regression trees (MRT) (Figure 3). MRT formed clusters of sites with similar species composition according to topographic variables. Four geographical attributes and the abundance of 77 species ( $>25$ individuals) were chosen for habitat classification using the package "mvpart" in R [4]. 


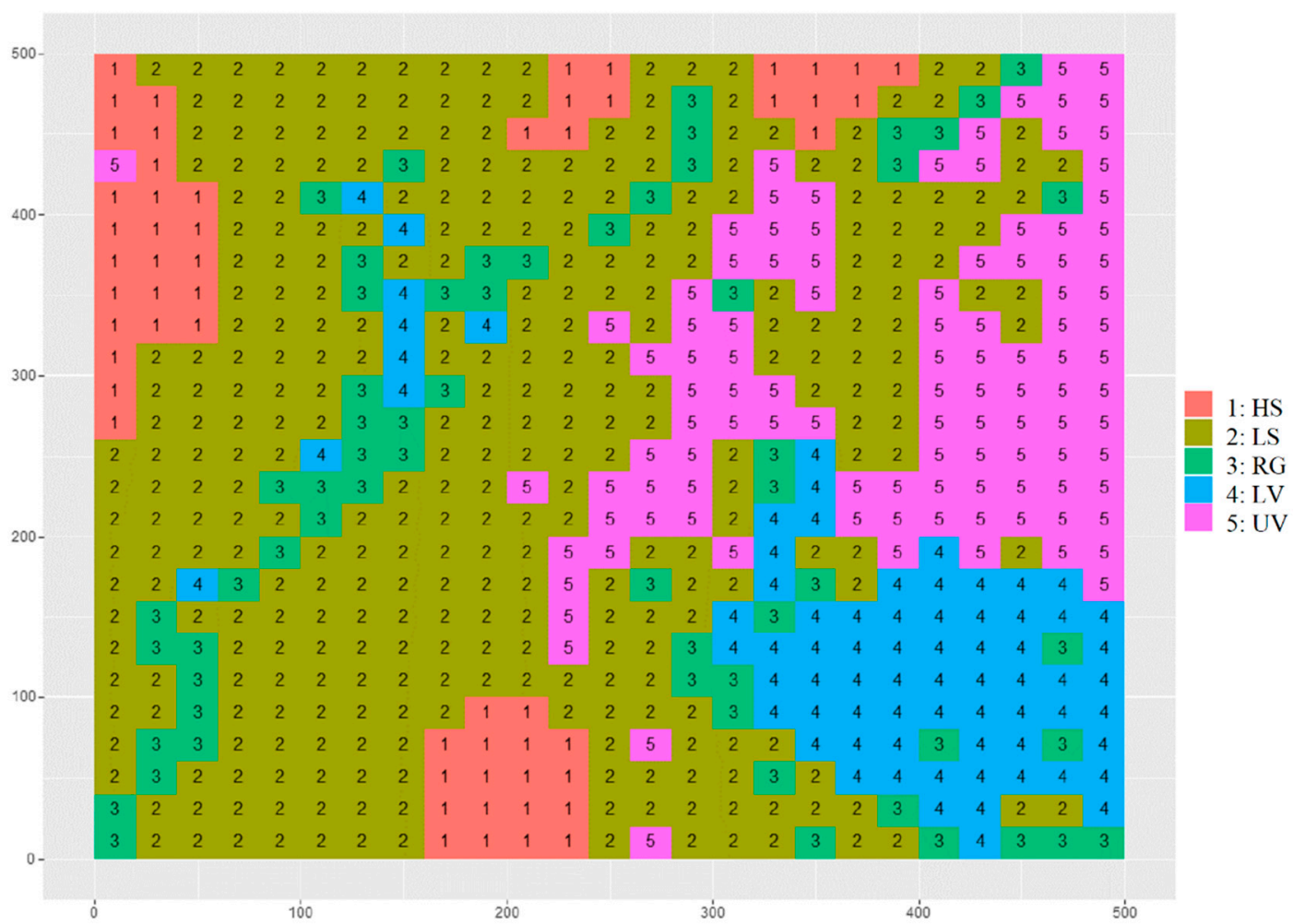

Figure 3. Habitats of the 25-ha Qinling plot based on $62520 \mathrm{~m} \times 20 \mathrm{~m}$ cells. HS: high-slope, LS: low-slope, RG: ridge, LV: low-valley, UV: upper-valley.

\subsection{Habitat Associations across Life Stages}

Torus-translation test was proposed by Harms, et al. [10] to explore significant association of a species with one or more habitats. As the position of tree individuals was not transformed, the entire habitat map was translated in four cardinal directions (up, down, left, and right) by $20 \mathrm{~m}$ increment to obtain the expected relative density of focal species within each simulated habitat map. In total, 2499 translated maps were produced and then the expected relative densities within each habitat were ranked from the largest to smallest. If the frequency distribution of true relative density in focal habitat was greater or smaller than at least $97.5 \%$ of simulated relative densities, with a significance level of $\alpha=0.05$ for two-tailed test, it was then confirmed to be significantly positive or negative associations with the focal habitat.

\subsection{Variation Partitioning of Dominant Species}

Based on redundancy analysis (RDA), the variation in the data matrix of species abundance were decomposed into dissimilar fractions, which were explained by variation in the topographic and spatial variables. Topographic variables controlled on spatial structures in species assemblages according to the niche theory, while the spatial structures in communities might also be generated by dispersal limitation which led to spatial autocorrelation in species data and could be detected by spatial variables [4]. The spatial variables were represented by principal coordinates of neighbor matrices (PCNMs). For each $20 \mathrm{~m} \times 20 \mathrm{~m}$ sub-plot, PCNMs were generated to describe all possible scale spatial components by a principal coordinate analysis (PCoA) of a truncated geographic distance matrix between 625 points of the spatial grid [27]. For topographic variables, the third-degree polynomial function of three variables (elevation, convexity, slope) was used to allow non-linear relationships between topographic variables and species abundance [4]. Aspect was a circular variable; cos(aspect) and $\sin$ (aspect) were computed to make the circular variable linear. In total, 11 variables were obtained in the expanded topographic data table. Response variables consisted of eigenfunctions 
of species abundance. Explanatory variables were represented by eigenfunctions of topographic and spatial variables (PCNMs). Due to the influence of the number of explanatory variables on correlation coefficients ( $R^{2}$ values), the adjusted $R^{2}$ values were used to measure the unbiased number of explanatory variables. Forward selection was used to remove the non-significant eigenfunctions of spatial and topographic variables [28]. Finally, purely topographic fraction [a] explained by topographic variables alone, spatially structured topographic fraction [b] explained by topographic and spatial variables combined, purely spatial fraction [c] explained by spatial variables alone, and unexplained fraction [d] were obtained.

\section{Results}

\subsection{Habitat Definition and Characteristics}

The 25-ha plot was characteristic of relatively complicated geographic structure (Figure 1), and it could be divided into five habitats: (1) high-slope; (2) low-slope; (3) ridge; (4) low-valley; (5) high-valley (Figure 3). The results of MRT indicated that habitats in the plot were mainly determined by three topographical variables (i.e., elevation, convexity, slope). The first split was determined by slope for habitats (break point $=20.88^{\circ}$ ), the second split was determined by elevation (break point $=1800 \mathrm{~m}$ ) and convexity (break point $=-1.31 \mathrm{~m}$ ), and the third split was based on elevation (break point $=$ $1769 \mathrm{~m}$ ) (Figure 4).

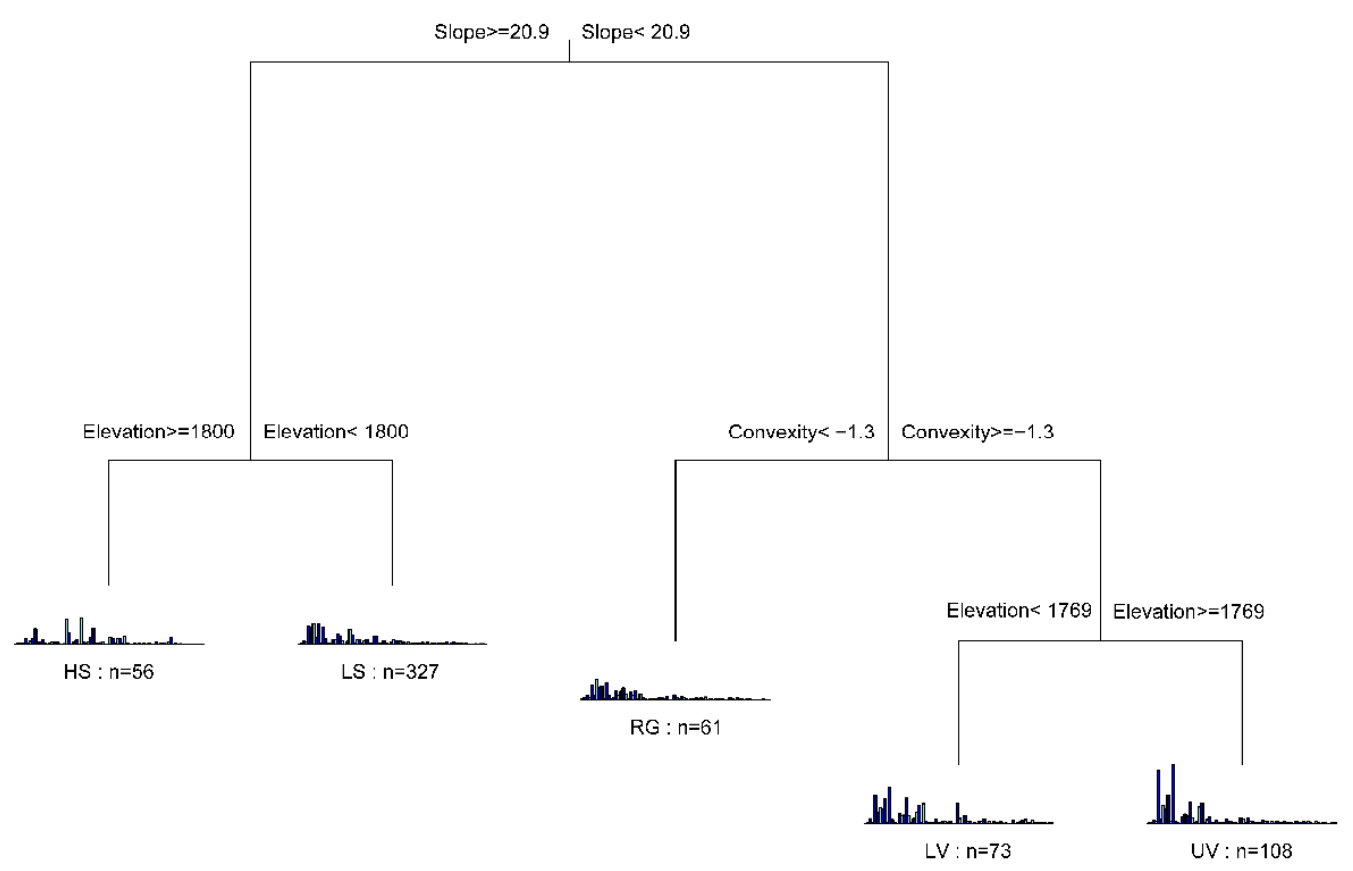

Figure 4. The result of multivariate regression trees of the 25-ha permanent forest dynamics plot in the Qinling Mountains, north-central China. The bar graphs show the species abundance in each habitat. HS: high-slope, LS: low-slope, RG: ridge, LV: low-valley, UV: upper-valley, $n$ : number of quarts in each habitat.

\subsection{Habitat Associations}

According to the torus-translation test, many species showed obvious preferences for the choice of specific habitats. Of the 16 dominant species, 12 species (75\%) were significantly positively or negatively associated with one or more habitats among all individuals (Table 2). For example, Quercus spinosa and Acer oliverianum showed strongly positive associations with the high-slope and low-slope habitat, respectively. However, Pinus armandii, Euptelea pleiospermum and Lindera obtusiloba were negatively associated with the low-valley habitat. Sorbus alnifolia was only positively associated with 
the upper-valley habitat and negatively associated with the low-slope habitat (Table 2). In addition, a total of 6 species showed positive associations with the upper-valley habitat, while there were no species showing significantly positive or negative associations with the ridge habitat among all individuals (Table 2).

Table 2. Torus-translation test for habitat associations of the 16 dominant species in the 25 -ha plot of the deciduous broad-leaved forest in the Qinling Mountains, north-central China. Total: All individuals with $\mathrm{DBH} \geq 1 \mathrm{~cm}$; Juveniles: Individuals with $\mathrm{DBH}<\mathrm{DBH} 99^{1 / 2}$; Adults: Individuals with DBH $>$ DBH99²/3. HS: high-slope, LS: low-slope, RG: ridge, LV: low-valley, UV: upper-valley. "+" represents significantly positive association, " -" indicates significantly negative association $(\alpha=0.05)$.

\begin{tabular}{|c|c|c|c|}
\hline \multirow{2}{*}{ Species } & \multicolumn{3}{|c|}{ Habitat Association } \\
\hline & Total & Juveniles & Adults \\
\hline Pinus armandii & $\mathrm{LV}-$ & $\mathrm{HS}+/ \mathrm{RG}-$ & RG- \\
\hline Populus purdomii & & & HS- \\
\hline Pterocarya insignis & & $\mathrm{HS}-/ \mathrm{RG}+$ & \\
\hline Carpinus cordata & & HS- & \\
\hline Quercus aliena & $\mathrm{UV}+$ & $\mathrm{RG}-/ \mathrm{UV}+$ & \\
\hline Quercus spinosa & HS+ & RG-/UV+ & $\mathrm{HS}+/ \mathrm{RG}-$ \\
\hline Euptelea pleiospermum & $\mathrm{LV}-/ \mathrm{UV}-$ & $\mathrm{LS}+/ \mathrm{RG}-/ \mathrm{LV}-$ & $\mathrm{LS}+/ \mathrm{RG}-/ \mathrm{LV}-/ \mathrm{UV}-$ \\
\hline Lindera obtusiloba & LV- & HS- & RG-/LV-/UV+ \\
\hline Cotoneaster acutifolius & HS- /LS- & HS- & HS- \\
\hline Prunus conadenia & UV+ & & $\mathrm{LS}-/ \mathrm{RG}+$ \\
\hline Sorbus alnifolia & LS-/UV+ & $\mathrm{LS}-/ \mathrm{LV}+/ \mathrm{UV}+$ & \\
\hline Acer oliverianum & LS+ & & LV- \\
\hline Meliosma cuneifolia & & HS- & HS- /LS+ \\
\hline Bothrocaryum controversum & $\mathrm{HS}-/ \mathrm{UV}+$ & & UV+ \\
\hline Dendrobenthamia japonica & UV+ & $\mathrm{HS}-/ \mathrm{LS}-/ \mathrm{RG}-/ \mathrm{UV}+$ & UV+ \\
\hline Symplocos paniculata & $\mathrm{HS}-/ \mathrm{UV}+$ & HS-/UV+ & HS-/UV+ \\
\hline
\end{tabular}

A large number of species showed obviously different habitat preferences at the two life stages. However, only three specie showed a consistent preference to habitat across the two life stages (Table 2). Populus purdomii, Pterocarya insignis and Carpinus cordata showed no apparently distributional biases with respect to habitat boundaries among all individuals compared to habitat preferences at juvenile or adult stage (Table 2). There were 21 and 24 significant associations at adult and juvenile stage, respectively (Table 2). For each habitat, the number of significant associations (positive or negative) were different among all individuals and at the two life stages. 15 positive associations coupled with only 2 negative associations were recorded in upper-valley habitat, while the highest number of negative associations were detected in high-slope habitat (Table 2).

\subsection{Variation Partitioning}

The total composition variation in species abundance was partitioned into the proportions explained by topographic variables alone [a], spatial variables alone [c], and topographic and spatial variables combined [b] (Figure 5). The proportions of total explained variation of community composition $[a+b+c]$ were $67 \%, 37 \%$ and $72 \%$ overall and at juvenile and adult, respectively. However, a large portion of variation was still undetermined [d] for all individuals at the two life stages (Figure 5). The contributions of topographic variables $[a+b]$ to total variation of community composition decreased systematically with trees maturing from juvenile to adult; however, variation explained by topographic variables alone [a] was negligible $(<2 \%)$. In addition, the fraction of variation determined by spatial variable alone [c] in community composition was especially higher for juveniles than adults (Figure 5). 

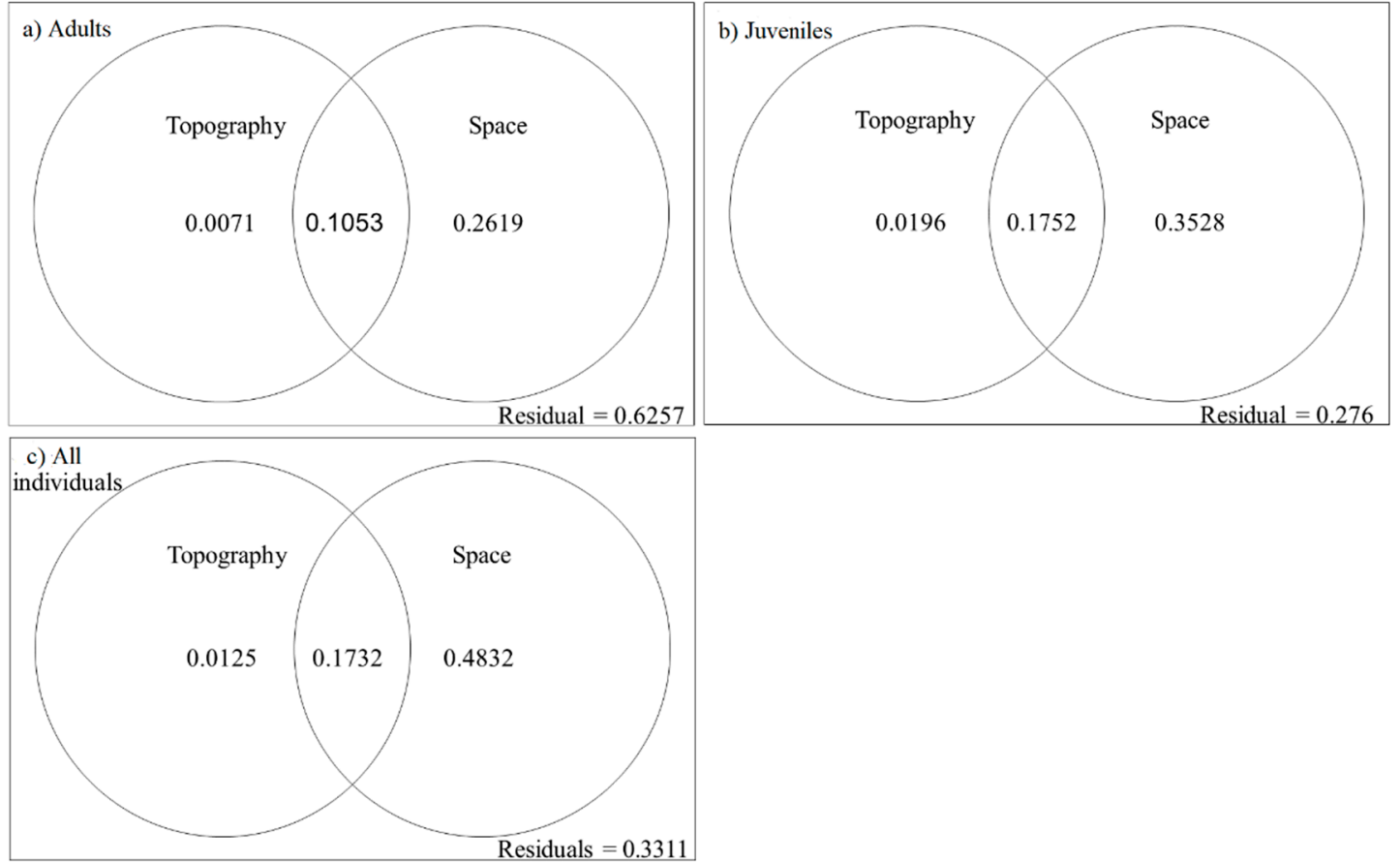

Figure 5. Variation partition of the 16 dominant tree species. The numbers in the circles indicate the portion of variation explained by topographic and spatial variables, respectively.

Similarly, the total topography fractions $[a+b]$ of juvenile stage for many species were larger than those of adult stage, especially for P. armandii, C. cordata, Q. spinosa, Cotoneaster acutifolius, S. alnifolia, Meliosma cuneifolia and Symplocos paniculate (Figure 6).

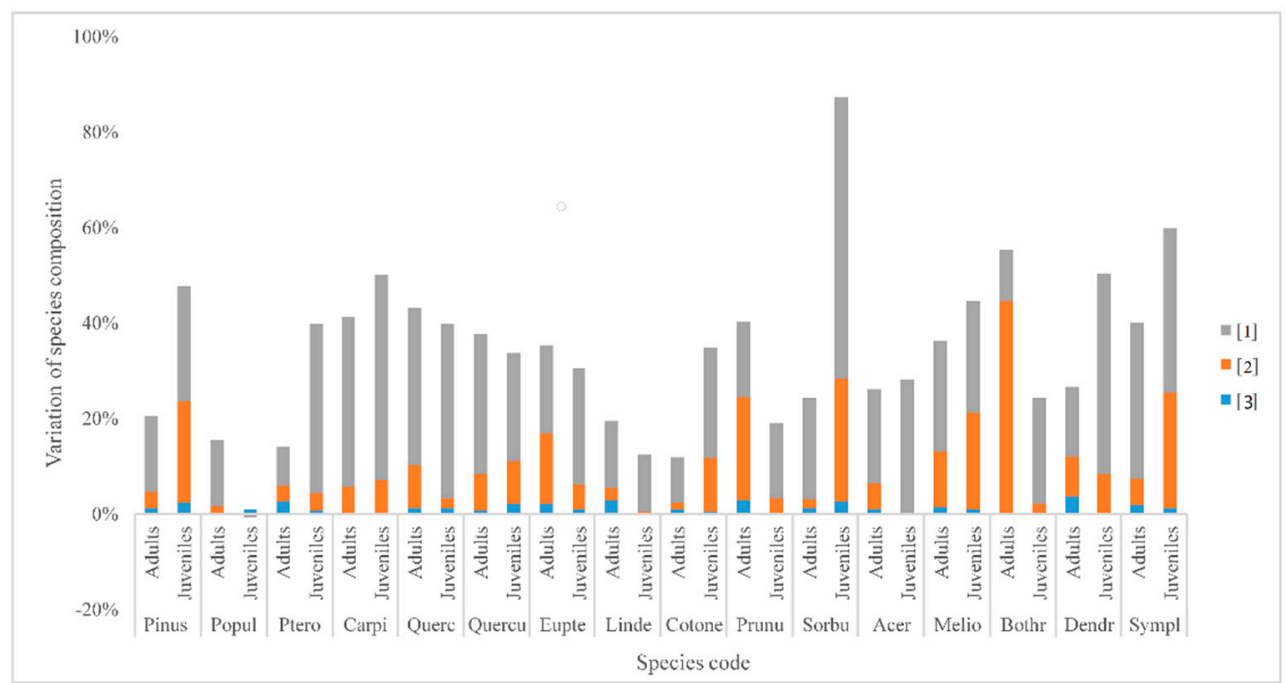

Figure 6. The variance explained by topographic and spatial variables for the each species at different life stages in the 25-ha permanent forest dynamics plot in the Qinling Mountains, north-central China. See Table 1 for species code. [1], purely spatial fraction [c]; [2], spatially structured topographic fraction [b]; [3], purely topographic fraction [a].

\section{Discussion}

\subsection{Habitat Definition and Structure in the 25-ha Plot}

Topography was an important driver in shaping species distribution along the ridge-valley gradients in the forest dynamics plot in the Qinling Mountains. Similar to other permanent forest 
dynamics plots with an area of over 24 ha in China and Panama [4,14], the Qinling forest dynamics plot was also structured into five habitats.

In some recent studies, multivariate regression trees (MRT) have been used in tropical, subtropical and temperate forests. In our studied forest, the MRT analyses indicated that slope, elevation and convexity were the three most important geographic factors responsible for habitat structuring (Figure 2). Daws, et al. [6] and Engelbrecht, et al. [29] proposed that topography could result in the differences in spatial patterns of environment condition, especially soil water availability. Although the relationships between topography and soil resource were inconsistent in different studies [30-32], they might be ubiquitous among the slope, elevation, convexity and soil resource in our studied forest. Soil chemical and physical properties were greatly affected by soil moisture. Suitable water availability of soil might lead to an increase in hydrolysis of ion [33], which partially resulted in the dependence of species distribution on the spatial structure of soil moisture.

\subsection{Habitat Associations}

12 of the 16 dominant tree species (75\%) in the Qinling plot had significant habitat preferences to at least one habitat among all individuals, which was similar to the Sinharaja forest dynamics plot (60 ha) in Sri Lanka [34] and the Gutianshan forest dynamics plot (24 ha) in China [35]. Compared to the elevation range in these plots (151 $\mathrm{m}$ in the Sinharaja plot and $269 \mathrm{~m}$ in the Gutianshan plot), the geographic condition in the Qinling plot was relatively simple, which was in sharp agreement with the relatively moderate associations between species distribution and topographic habitats.

At species level, high mortality rate as small trees grew into large ones might be a possible reason for the species' positive association with a given habitat only at juvenile stage [7,35]. In other words, there might be a high density of reproductive adults in the adjacent sites, and seedlings were widely dispersed and established but suffered from a low survival rate. For example, as the tree size increased, the negative density dependence would appear and outweigh the benefits of the favorable habitats. For species such as M. cuneifolia and Q. spinosa showing significantly positive habitat associations only at adult stage, the subsequent loss of associations at former life stage would result from low seedling establishment or little chance of recruitment within the given habitats [7]. Webb and Peart [12] considered that the lack of associations at small stage was attributable to the unsuccess of seed dispersal and seedling establishment outside of favorable habitats. Alternatively, for species with consistent associations across all life stages, seed dispersal limitation might be responsible for the consistent habitat preferences, which caused juveniles to be located near adults [12].

Trees maturing from juvenile to adult required a long time and might be subject to marked changes in environmental conditions [14]. Therefore, tree species with the differences in habitat associations across multiple life stages might be due to ontogenetic niche shifts in resource requirements [7]. Juveniles were mostly distributed near the parent trees as a result of dispersal limitation. With the increasing tree size, the effect of seed dispersal limitation decreased, and the topographic effects on species distribution became intensified, thereby the selection of suitable habitats resulted in the changes of habitat associations [36]. In addition, the forests in our studied site were logged several times during the time period from the 1790s to 1870s [37]. Most of old trees were selectively cut, which might change species composition. Thus, a site that favored the establishment of saplings of a focal species might have changed to favor the establishment of other species, resulting in alteration in local tree species distribution and habitat associations.

The ability of species to adapt to the five topographic habitats was different. The upper-valley habitats were characterized with enough sunlight conditions in our studied forest. Therefore, the notably higher number of positive associations across both life stages occurred at the upper-valley habitat (Table 2). Due to the high density of large trees and topographic factors, the relatively poor sunlight condition was ubiquitous in low-valley habitat, which restrained seedling establishment [38]. Slope habitat were characteristic of sufficient water, lower nutrients loss for species growth [39]. The lower number of detected positive associations in ridge habitat at adult stage (Table 2) might result 
from the fact that the lower survival of these species with drought sensitivity in the drier habitats over time. The obvious differences in habitat associations with upper-valley and ridge habitats suggested that niche differentiation of ontogenetic requirement contributed to species distribution.

\subsection{The Contribution of Topographic and Spatial Variables to Species Distribution}

In this study, the role of niche and dispersal limitation in structuring the forest community in the Qinling plot was revealed by partitioning the variation in species composition at different life stages into different fractions, showing that a large portion ( $>37 \%)$ of total variation of species distribution $[a+b+c]$ in the Qinling plot was determined by topographic and spatial variables for all individuals and for the two life stages (Figure 5).

It was notable that variation determined by topographic structure $[a+b]$ was $19 \%$ for the juveniles, but only $11 \%$ for the adults. The potential reason was that habitat filtering might be the dominant driving force in community assembly processes at the juvenile life stage. Although the spatial distribution of juveniles might be determined to a large extent by habitat filtering at juvenile stage [25], it would be subject to the increasing density-dependent mortality during the transformation from juvenile to adult stage [35]. Seedlings and saplings were widely dispersed and established, while the mortality rates caused by negative density dependence increased with trees maturing from juvenile to adult outside the optimal habitats, which might weaken the habitat associations with adult trees [12]. Alternatively, given the lower variation explained by topographic component $[a+b]$ at later stage in species composition, adult trees might be more responsive to the unmeasured habitat components such as soil resource that caused the unexplained fraction [d] [40].

Purely spatial fraction [c] of compositional variation has usually been considered to be attributed to the effects of dispersal-assembly and species response to unmeasured environment variation [13]. Being independent from topographic variables $[a+b]$, spatial variables alone [c] contributed largely to the total variation in species composition. This might indicate that dispersal effects in our forest was strong. For example, P. armandii had pinecones with seeds inside and could mainly be dispersed by animals and gravity. On the other hand, there was a sharp contrast to the proportion of variation explained by spatial variables alone [c] and topographic variables [a + b] (Figure 5), suggesting that dispersal limitation might play a more important role in community assemblage or species distribution in the deciduous broad-leaved forest in the Qinling Mountains, which was consistent with many previous studies [41-43]. However, it was worth noting that the purely spatial fraction [c] also included the unobserved spatially structured habitat variables such as soil condition and directional dispersal of propagules, which were not correlated with topography [4].

It was not surprising that a large fraction of total variation for each species was unexplained [d] (Figure 6). One reason was that non-spatially structured biological and environmental variables were unmeasured and not included in the analyses. Meanwhile, the potential topographic variables such as biotic conditions and light resources under $20 \mathrm{~m} \times 20 \mathrm{~m}$ scale might not be fully captured [25]. In addition, stochastic process could also be responsible for the unexplained variation [d].

\section{Conclusions}

In this study, we found strong evidence that topographic variables, especially elevation, convexity, and slope constrained the distribution of tree species. The majority of species showed obvious habitat preferences. The contributions of topographic and spatial component to the distribution structure of tree species varied across life stages in the deciduous broad-leaved forest in the Qinling Mountains of north-central China. The large proportion of purely spatial variation [c] for species distribution might indicate the assembly process of these species was largely driven by mechanisms related to dispersal limitation. 
Author Contributions: Conceptualization, H.D.; Data curation, H.S.; Formal analysis, H.S.; Funding acquisition, H.D.; Investigation, F.X., Q.Z. (Quan Zhou), X.S. and S.F.; Methodology, X.S. and K.Z.; Resources, C.D.; Validation, F.X. and H.D.; Visualization, Q.Z. (Quanfa Zhang) and K.Z.; Writing—original draft, H.S.; Writing一review \& editing, H.D.

Funding: This research was supported by the National Natural Science Foundation of China $(31770517,31470521)$ and the Biodiversity Committee of the Chinese Academy of Sciences.

Acknowledgments: We would like to thank Senior Engineer Gaodi Dang and Zhenhai Wu for species identification. We thank many field workers for their contributions to the establishment and census of the 25-ha permanent forest plot. We also thank the Foping National Nature Reserve for logistical support during the field work.

Conflicts of Interest: The authors declare no conflict of interest.

\section{References}

1. Tilman, D. Resource competition and community structure. Monogr. Popul. Biol. 1982, 17, 1-296. [PubMed]

2. Leibold, M.A.; McPeek, M.A. Coexistence of the niche and neutral perspectives in community ecology. Ecology 2006, 87, 1399-1410. [CrossRef]

3. Keddy, P.A. Assembly and response rules: Two goals for predictive community ecology. J. Veg. Sci. 1992, 3, 157-164. [CrossRef]

4. Legendre, P.; Mi, X.; Ren, H.; Ma, K.; Yu, M.; Sun, I.F.; He, F. Partitioning beta diversity in a subtropical broad-leaved forest of China. Ecology 2009, 90, 663-674. [CrossRef]

5. Whittaker, R.H. Vegetation of the Great Smoky Mountains. Ecol. Monogr. 1956, 26, 1-69. [CrossRef]

6. Daws, M.I.; Mullins, C.E.; Burslem, D.F.R.P.; Paton, S.R.; Dalling, J.W. Topographic position affects the water regime in a semideciduous tropical forest in Panamá. Plant Soil 2002, 238, 79-89. [CrossRef]

7. Comita, L.S.; Condit, R.; Hubbell, S.P. Developmental changes in habitat associations of tropical trees. J. Ecol. 2007, 95, 482-492. [CrossRef]

8. De'Ath, G. Multivariate regression trees: A new technique for modeling species-environment relationships. Ecology 2002, 83, 1105-1117. [CrossRef]

9. Baldeck, C.A.; Harms, K.E.; Yavitt, J.B.; John, R.; Turner, B.L.; Valencia, R.; Navarrete, H.; Bunyavejchewin, S.; Kiratiprayoon, S.; Yaacob, A.; et al. Habitat filtering across tree life stages in tropical forest communities. Proc. Biol. Sci. 2013, 280, 20130548. [CrossRef] [PubMed]

10. Harms, K.E.; Condit, R.; Hubbell, S.P.; Foster, R.B. Habitat associations of trees and shrubs in a 50-ha neotropical forest plot. J. Ecol. 2001, 89, 947-959. [CrossRef]

11. Wang, Q.G.; Punchi-Manage, R.; Lu, Z.J.; Franklin, S.B.; Wang, Z.H.; Li, Y.Q.; Chi, X.L.; Bao, D.C.; Guo, Y.L.; Lu, J.M.; et al. Effects of topography on structuring species assemblages in a subtropical forest. J. Plant Ecol. 2017, 10, 440-449. [CrossRef]

12. Webb, C.O.; Peart, D.R. Habitat associations of trees and seedlings in a Bornean rain forest. J. Ecol. 2000, 88, 464-478. [CrossRef]

13. Baldeck, C.A.; Harms, K.E.; Yavitt, J.B.; John, R.; Turner, B.L.; Valencia, R.; Navarrete, H.; Davies, S.J.; Chuyong, G.B.; Kenfack, D.; et al. Soil resources and topography shape local tree community structure in tropical forests. Proc. Biol. Sci. 2013, 280, 20122532. [CrossRef] [PubMed]

14. Kanagaraj, R.; Wiegand, T.; Comita, L.S.; Huth, A. Tropical tree species assemblages in topographical habitats change in time and with life stage. J. Ecol. 2011, 99, 1441-1452. [CrossRef]

15. Punchi-Manage, R.; Getzin, S.; Wiegand, T.; Kanagaraj, R.; Gunatilleke, C.V.S.; Gunatilleke, I.A.U.N.; Wiegand, K.; Huth, A. Effects of topography on structuring local species assemblages in a Sri Lankan mixed dipterocarp forest. J. Ecol. 2013, 101, 149-160. [CrossRef]

16. Webb, C.O.; Ackerly, D.D.; McPeek, M.A.; Donoghue, M.J. Phylogenies and community ecology. Annu. Rev. Ecol. Syst. 2002, 33, 475-505. [CrossRef]

17. Gilbert, B.; Lechowicz, M.J. Neutrality, niches, and dispersal in a temperate forest understory. Proc. Natl. Acad. Sci. USA 2004, 101, 7651-7656. [CrossRef] [PubMed]

18. Lan, G.Y.; Hu, Y.H.; Cao, M.; Zhu, H. Topography related spatial distribution of dominant tree species in a tropical seasonal rain forest in China. For. Ecol. Manag. 2011, 262, 1507-1513. [CrossRef] 
19. Liu, Y.U.; Linderholm, H.W.; Song, H.; Cai, Q.; Tian, Q.; Sun, J.; Chen, D.; Simelton, E.; Seftigen, K.; Tian, H.U.A.; et al. Temperature variations recorded inPinus tabulaeformistree rings from the southern and northern slopes of the central Qinling Mountains, central China. Boreas 2009, 38, 285-291. [CrossRef]

20. Dang, H.S.; Jiang, M.X.; Zhang, Q.F.; Zhang, Y.J. Growth responses of subalpine fir (Abies fargesii) to climate variability in the Qinling Mountain, China. For. Ecol. Manag. 2007, 240, 143-150. [CrossRef]

21. Yue, M.; Dang, G.; Gu, T. Vertical zone spectrum of vegetation in Foping National Reserve and the comparison with the adjacent areas. J. Wuhan Bot. Res. 2000, 18, 375-382.

22. Zhang, K.R.; Dang, H.S.; Tan, S.D.; Wang, Z.X.; Zhang, Q.F. Vegetation community and soil characteristics of abandoned agricultural land and pine plantation in the Qinling Mountains, China. For. Ecol. Manag. 2010, 259, 2036-2047. [CrossRef]

23. Du, X.C.; Ren, Y.; Dang, G.D.; Lundholm, J. Distribution and plant community associations of the understory bamboo Fargesia qinlingensis in the Foping National Nature Reserve, China. Ann. For. Sci. 2011, 68, 1197-1206. [CrossRef]

24. Bagchi, R.; Henrys, P.A.; Brown, P.E.; Burslem, D.F.; Diggle, P.J.; Gunatilleke, C.V.; Gunatilleke, I.A.; Kassim, A.R.; Law, R.; Noor, S.; et al. Spatial patterns reveal negative density dependence and habitat associations in tropical trees. Ecology 2011, 92, 1723-1729. [CrossRef] [PubMed]

25. Punchi-Manage, R.; Wiegand, T.; Wiegand, K.; Getzin, S.; Gunatilleke, C.V.S.; Gunatilleke, I.A.U.N. Effect of spatial processes and topography on structuring species assemblages in a Sri Lankan dipterocarp forest. Ecology 2014, 95, 376-386. [CrossRef] [PubMed]

26. Yamakura, T.; Kanzaki, M.; Itoh, A.; Ohkubo, T.; Ogino, K.; Chai, E.O.K.; Seng, L.H.; Shaw, A.P. Topography of a Large-Scale Research Plot Established within a Tropical Rain Forest at Lambir, Sarawak. Tropics 1995, 5, 41-56. [CrossRef]

27. Gower, J.C. Some Distance Properties of Latent Root and Vector Methods Used in Multivariate Analysis. Biometrika 1966, 53, 325-338. [CrossRef]

28. Blanchet, F.G.; Legendre, P.; Borcard, D. Forward selection of explanatory variables. Ecology 2008, 89, 2623-2632. [CrossRef]

29. Engelbrecht, B.M.; Comita, L.S.; Condit, R.; Kursar, T.A.; Tyree, M.T.; Turner, B.L.; Hubbell, S.P. Drought sensitivity shapes species distribution patterns in tropical forests. Nature 2007, 447, 80-82. [CrossRef]

30. Helvey, J.D.; Hewlett, J.D.; Douglass, J.E. Predicting Soil Moisture in the Southern Appalachians. Soil Sci. Soc. Am. J. 1972, 36, 954-959. [CrossRef]

31. Hewlett, J.D.; Hibbert, A.R. Moisture and Energy Conditions within a Sloping Soil Mass during Drainage. J. Geophys. Res. 1963, 68, 1081-1087. [CrossRef]

32. Becker, P.; Rabenold, P.E.; Idol, J.R.; Smith, A.P. Water potential gradients for gaps and slopes in a Panamanian tropical moist forest's dry season. J. Trop. Ecol. 1988, 4, 173-184. [CrossRef]

33. Fotovat, A.; Naidu, R.; Sumner, M.E. Water:Soil ratio influences aqueous phase chemistry of indigenous copper and zinc in soils. Aust. J. Soil Res. 1997, 35, 687-709. [CrossRef]

34. Gunatilleke, C.V.S.; Gunatilleke, I.A.U.N.; Esufali, S.; Harms, K.E.; Ashton, P.M.S.; Burslem, D.F.R.P.; Ashton, P.S. Species-habitat associations in a Sri Lankan dipterocarp forest. J. Trop. Ecol. 2006, 22, 371-384. [CrossRef]

35. Lai, J.S.; Mi, X.C.; Ren, H.B.; Ma, K.P. Species-habitat associations change in a subtropical forest of China. J. Veg. Sci. 2009, 20, 415-423. [CrossRef]

36. Hu, Y.H.; Sha, L.Q.; Blanchet, F.G.; Zhang, J.L.; Tang, Y.; Lan, G.Y.; Cao, M. Dominant species and dispersal limitation regulate tree species distributions in a 20-ha plot in Xishuangbanna, southwest China. Oikos 2012, 121, 952-960. [CrossRef]

37. Zhang, Y. Shaanxi Forest; Xi'an Science and Technology Press: Xi'an, China, 1989. (In Chinese)

38. Denslow, J.S.; Guzman, G.S. Variation in stand structure, light and seedling abundance across a tropical moist forest chronosequence, Panama. J. Veg. Sci. 2000, 11, 201-212. [CrossRef]

39. Liu, Q.; Bi, L.; Song, G.; Wang, Q.; Jin, G. Species-habitat associations in an old-growth temperate forest in northeastern China. BMC Ecol. 2018, 18, 20. [CrossRef] [PubMed]

40. Paoli, G.D.; Curran, L.M.; Zak, D.R. Soil nutrients and beta diversity in the Bornean Dipterocarpaceae: Evidence for niche partitioning by tropical rain forest trees. J. Ecol. 2006, 94, 157-170. [CrossRef]

41. Borcard, D.; Legendre, P.; Drapeau, P. Partialling out the Spatial Component of Ecological Variation. Ecology 1992, 73, 1045-1055. [CrossRef] 
42. Svenning, J.C.; Kinner, D.A.; Stallard, R.F.; Engelbrecht, B.M.J.; Wright, S.J. Ecological determinism in plant community structure across a tropical forest landscape. Ecology 2004, 85, 2526-2538. [CrossRef]

43. Chust, G.; Chave, J.; Condit, R.; Aguilar, S.; Lao, S.; Pérez, R. Determinants and spatial modeling of tree $\beta$-diversity in a tropical forest landscape in Panama. J. Veg. Sci. 2006, 17, 83-92. [CrossRef] 